\title{
The omitted symptoms challenge the diagnosis of right atrial myxoma: a case report
}

\author{
Shulun Ma ${ }^{1,2}$, Qian Xu1, Ruizheng Shi ${ }^{2}$, Xin Zhang ${ }^{1}$ and Xuliang Chen ${ }^{1 *}$
}

\begin{abstract}
Background: Cardiac myxoma (CM) is the most common type of primary cardiac tumors. The prevalence of primary cardiac tumors is $0.0017-0.28 \%$ in various autopsy studies. The clinical symptoms of CM which includes embolism, intracardiac obstruction, general or constitutional manifestations and infected myxoma are largely depended on the size, growing speed, location and pedicle length of the tumor. The following case reported a missed diagnostic case of a right atrial myxoma firstly presented digestive, systemic symptoms and immunologic disorder, leading to emergent tricuspid valves obstruction situation.

Case presentation: We reported a critical case of a 51-year-old female with CM was firstly admitted to the gastroenterology clinical department because of poor appetite, marked fatigability and weight loss for 2 months. The physician diagnosed her as chronic gastritis and treated her with some symptomatic treatment such as ilaprazole and magnesium aluminum carbonate. After months without definitive diagnosis, this right atrial myxoma grew into right ventricle and obstructed the tricuspid valves, causing her dyspnea, sweating, dizziness, feeling of impending death when she was sleeping. Transthoracic echocardiogram revealed a $6.1 \times 4.2 \times 3.7 \mathrm{~cm}^{2}$ mass adjacent to tricuspid valves. The patient underwent surgical excision and pathology revealed a primary cardiac myxoma.
\end{abstract}

Conclusion: This case reported a critical result of missed diagnosis of right atrial myxoma and showed its systematic symptoms and immunologic disorder, highlighting the importance of systematic examinations on patients. Furthermore, it appeals early diagnosis of CM and consideration of drug targets to suppress CM development.

Keywords: Myxoma, Diagnosis, Symptoms

\section{Background}

Cardiac myxoma $(\mathrm{CM})$ is the most common type of primary cardiac tumors. The prevalence of primary cardiac tumors is $0.0017-0.28 \%$ in various autopsy studies [1]. The clinical symptoms of CM which includes embolism, intracardiac obstruction, general or constitutional manifestations and infected myxoma are largely depended on

\footnotetext{
*Correspondence: chen-x104@163.com

'Department of Cardiovascular Surgery, Xiangya Hospital, Central South University, Xiangya Rd 87, Changsha 410008, China

Full list of author information is available at the end of the article
}

the size, growing speed, location and pedicle length of the tumor [2]. Thus, the various manifestations challenge the diagnosis of $\mathrm{CM}$ and even lead to critical results. Here, we reported a missed diagnostic case of a right atrial myxoma firstly presented digestive, systemic symptoms and immunologic disorder, which caused emergent tricuspid valves obstruction situation.

\section{Case presentation}

A 51-year-old female patient without special family history was admitted to the gastroenterology clinical department

(c) The Author(s). 2020 Open Access This article is licensed under a Creative Commons Attribution 4.0 International License, which permits use, sharing, adaptation, distribution and reproduction in any medium or format, as long as you give appropriate credit to the original author(s) and the source, provide a link to the Creative Commons licence, and indicate if changes were made. The images or other third party material in this article are included in the article's Creative Commons licence, unless indicated otherwise in a credit line to the material. If material is not included in the article's Creative Commons licence and your intended use is not permitted by statutory regulation or exceeds the permitted use, you will need to obtain permission directly from the copyright holder. To view a copy of this licence, visit http://creativecommons.org/licenses/by/4.0/ The Creative Commons Public Domain Dedication waiver (http://creativecommons.org/publicdomain/zero/1.0/) applies to the data made available in this article, unless otherwise stated in a credit line to the data. 
because of poor appetite, marked fatigability and weight loss for 2 months. Her physical examinations revealed no evidence of abnormalities: no edema or superficial varicosities. Cardiac exam revealed normal heart rate and rhythm without extra sounds or murmurs. No further cardiac examination was done based on her chief complaint and normal physical examinations. Her abdomen was soft. Superficial and deep palpation didn't find organomegaly or masses. The clinical examinations revealed normal results of blood routine, urine routine, stool routine, liver function and gastroscopic, except for slightly high globulin $(39.3 \mathrm{~g} / \mathrm{L})$ and low albumin $(28 \mathrm{~g} / \mathrm{L})$. Then, quantitative measurements of plasma immunoglobulin and coagulation were performed. The results showed plasma IgE was $413 \mathrm{IU} / \mathrm{mL}$ and IgG was $17.4 \mathrm{~g} / \mathrm{L}$. PTA (prothrombin activity) decreased to $56.8 \%$ while PT (prothrombin time) and fibrinogen increased to $14.5 \mathrm{~s}$ and $4.83 \mathrm{~g} / \mathrm{L}$ respectively. In order to exclude any hematological system diseases, bone marrow puncture was performed and result revealed elevated level of plasmocytes (8\%). The physician diagnosed her as chronic gastritis and treated her with some symptomatic treatment such as ilaprazole and magnesium aluminum carbonate. Finally, the patient felt better and left.

One month later, the woman suddenly felt dyspnea, sweating, dizziness and feeling of impending death when she was sleeping. The symptoms slightly relieved when she slept in left lateral position or sat up. She was referred to our hospital for emergency call and a series of clinical examinations were performed. Transthoracic echocardiogram revealed a mobile $6.1 \times 4.2 \times 3.7 \mathrm{~cm}^{2}$ mass with irregular borders and hyperechogenicity in the right heart, adjacent to the tricuspid valves (Fig. 1a-b). Half of the mass located in the atrium and the other half was in the ventricle. Obstructed by the mass, the tricuspid valves are unable to close which correlated with her tricuspid valves area systolic murmur. The transesophageal echocardiogram clearly showed the mass obstructed into the tricuspid valves (Fig. 1c-d, Video 1). The electrocardiogram demonstrated incomplete right bundle branch block, right atrium enlargement, II, III, avF ST depression and right deviation of electrocardio axis. Computed tomography result indicated that right atrium dilated. No pleural effusion and enlarged mediastinal lymph nodes were found. Magnetic resonance imaging was not performed because the patient was incapable of lying down.

At the time of perioperative period, the patient with apparent varicose chest vein had to maintain the left lateral position because of the mass obstruction (Fig. 2a-b). Even before the extracorporeal circulation, her systolic pressure had dropped maximal to $45 \mathrm{mmHg}$ for several
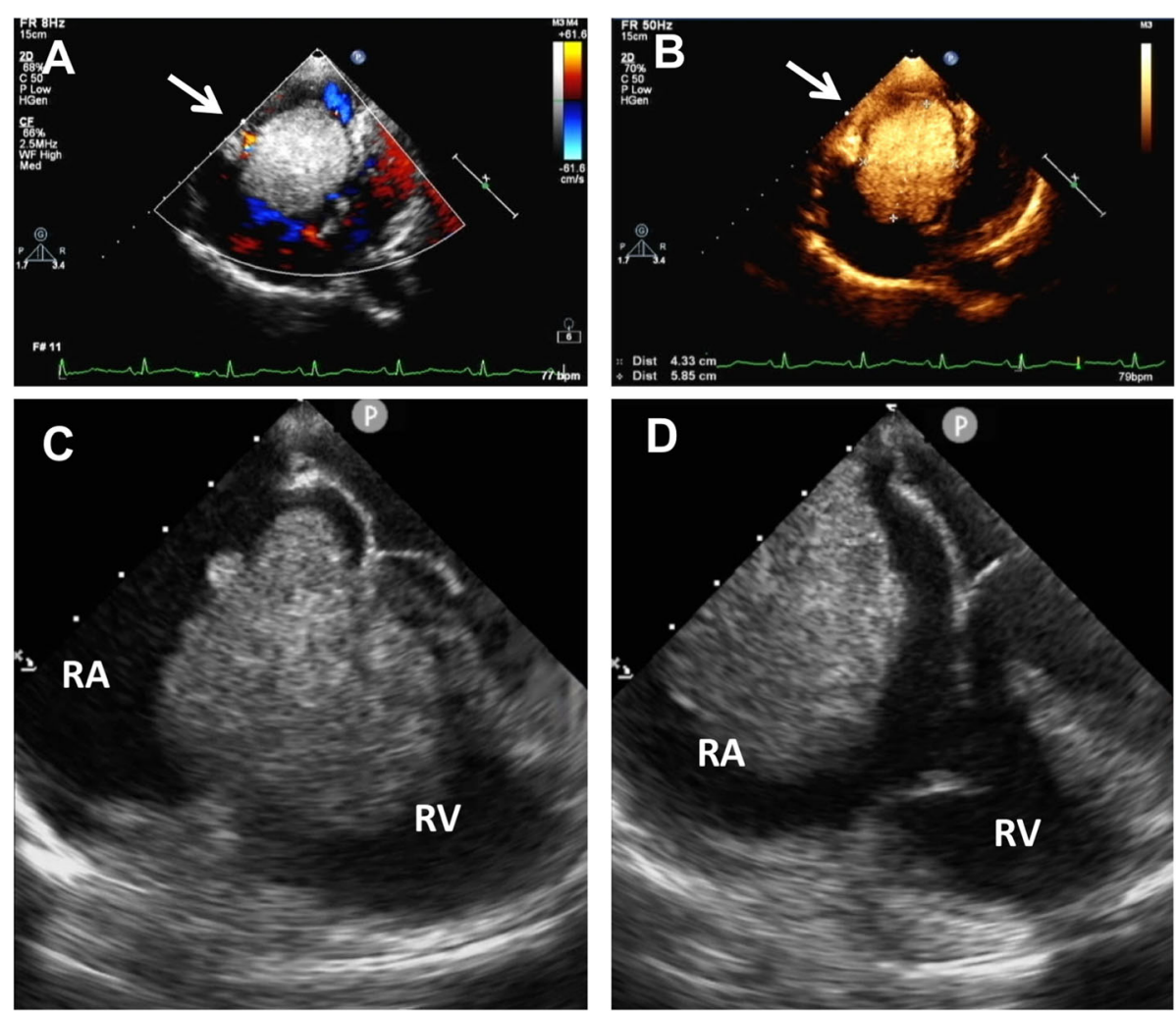

Fig. 1 Transthoracic echocardiography showed a giant mass (white arrow) in the right atrium (a-b). Transesophageal echocardiogram clearly showed the mass obstructed into the tricuspid valves and retracted to the right atrium afterwards (c-d). RA: right atrium; RV: right ventricle 


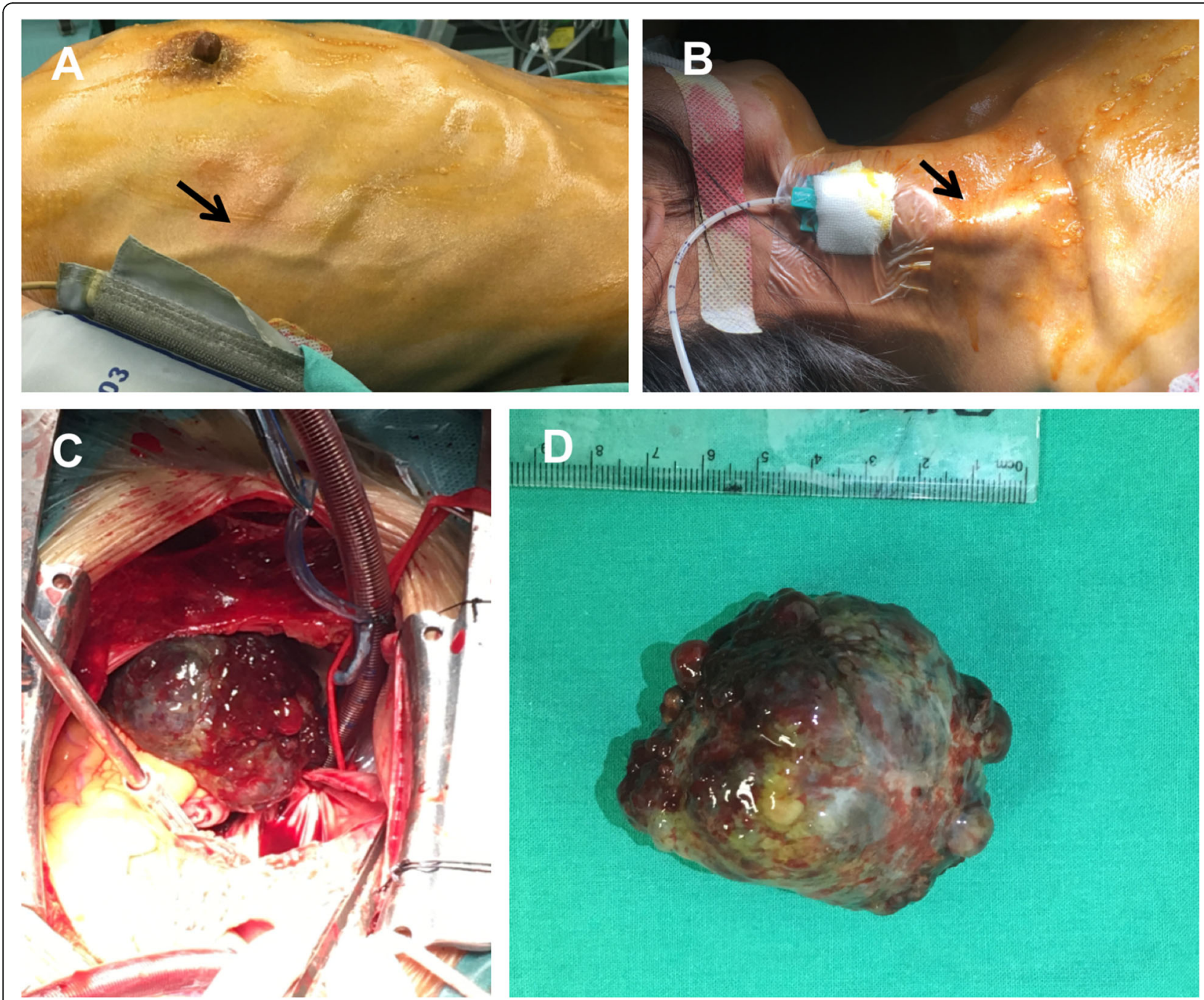

Fig. 2 The distention of chest wall (a) and jugular vessels (b) (black arrow) on patient. During the surgery, we found a giant right atrial myxoma measuring $65 \mathrm{~mm} \times 45 \mathrm{~mm} \times 35 \mathrm{~mm}$ was located adjacent to tricuspid valves (c, d)

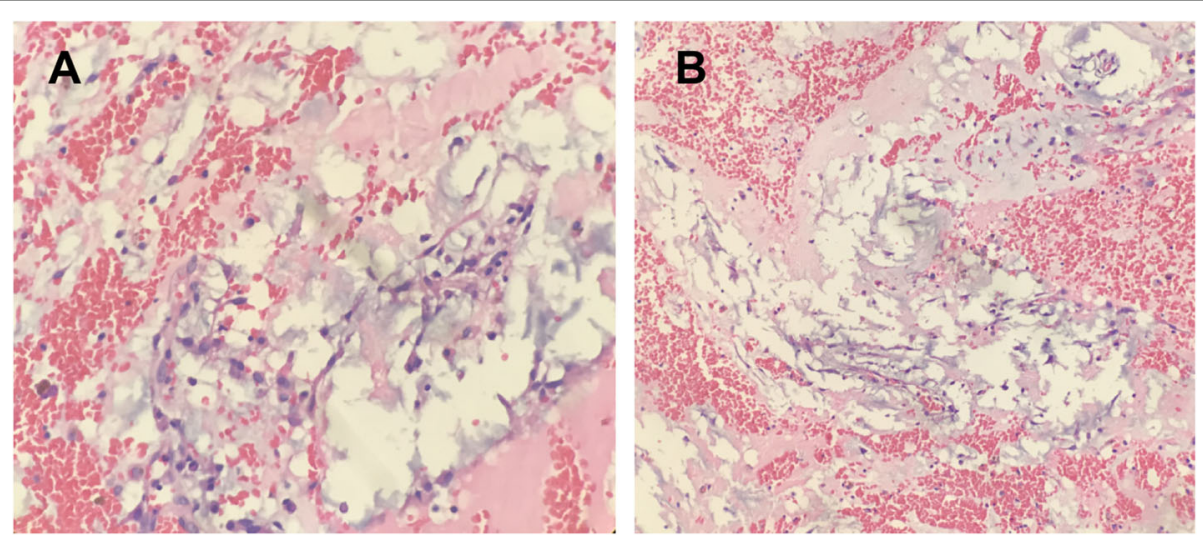

Fig. 3 Pathological examination showed star-shaped tumor cell with halos around them. Large scale of hemorrhage occurred in the myxoma (a, b). Magnification is $400 \times$ for $2 \mathrm{E}$ and $200 \times$ for $2 \mathrm{~F}$ 
times due to the obstruction of the tumor into the tricuspid valves. Extrusion of the tumor by hands immediately was effective and blood pressure returned to normal. At the end, the mass was removed and the patient's symptoms relieved (Fig. 2c-d). The pathological examination verified that the mass was a primary cardiac myxoma (Fig. 3a-b). She was discharged home 7 days after the operation and is currently asymptomatic and doing well after 12 months of follow-up.

\section{Discussion and conclusion}

Cardiac myxoma $(\mathrm{CM})$ is the most common type of primary cardiac tumors. About $75 \%$ of myxomas generate from the left atrium, $10-20 \%$ in the right atrium, and rarely in the ventricles $[1,3]$. In this case, the patient firstly presented digestive and systemic manifestations including weight loss, poor appetite and marked fatigability. It was considered due to autocrine cytokine production such as IL-6 and IL-8 [4]. Her auxiliary examination revealed a high immunoglobulin and increased plasmocytes in bone marrow. This might attribute to the hemorrhage or denaturation of the tumor which led to a series of immunological reactions. Other findings such as chronic hemolytic anemia, thrombocytopenia and polycythemia can also be seen in some cases $[5,6]$. These may lead to misdiagnosis of infective endocarditis, vasculitis, rheumatoid arthritis and other systemic diseases [7, 8]. When tumor size grows, it can present symptoms of intracardiac obstruction such as left and right heart failure $[9,10]$. The critical right $\mathrm{CM}$ in our case showed a severe tricuspid obstruction and lead to dyspnea, orthopnea and systemic congestion. Under this situation, surgery is the only effective treatment.

At present, 34 proteins markers are found to be involved in the histogenesis and development of CM [6]. And some potential drug targets such as CCR2, TGF $\beta$, MUC1, FGFR, EGFR, GATA4, HAND1, MYC, FOS and MMP9 were confirmed to be key nodes. Since CM development $[6,11]$ can be suppressed by blocking these targets, it is necessary to diagnose CM early in order to provide more treatment options and reduce mortality risk. This case reported a critical result of missed diagnosis of right atrial myxoma and showed its systematic symptoms and immunologic disorder, highlighting the importance of systematic examinations for early diagnosis on patients.

\section{Supplementary information}

Supplementary information accompanies this paper at https://doi.org/10. 1186/s12872-020-01413-4.

Additional file 1.

\section{Abbreviations}

CM: Cardiac myxoma; PT: Prothrombin time; PTA: Prothrombin activity
Acknowledgements

Not applicable.

\section{Authors' contributions}

SM and QX collected information and drafted the manuscript. XZ and RS revised the manuscript. XC did critical revision and made final approval of the manuscript. All authors read and approved the final manuscript.

\section{Funding}

This research did not receive any specific grant from funding agencies in the public, commercial, or not-for-profit sectors.

Availability of data and materials

The datasets used during the current study are available from the corresponding author on reasonable request.

\section{Ethics approval and consent to participate}

The entire case study was approved by the ethical department of Xiangya Hospital, Central South University. The patient was fully informed about the nature of this report and Informed Consent was signed by the patient.

\section{Consent for publication}

Written informed consent for publication of their clinical details and clinical images was obtained from the patient. A copy of the consent form is available for review by the Editor of this journal.

\section{Competing interests}

The authors declare that they have no competing interests.

\section{Author details}

${ }^{1}$ Department of Cardiovascular Surgery, Xiangya Hospital, Central South University, Xiangya Rd 87, Changsha 410008, China. ${ }^{2}$ Department of Cardiovascular Medicine, Xiangya Hospital, Central South University, Changsha, China.

Received: 26 February 2019 Accepted: 2 March 2020

Published online: 25 March 2020

\section{References}

1. Reynen K. Cardiac myxomas. N Engl J Med. 1995;333(24):1610-7.

2. Amano J, Kono T, Wada Y, Zhang T, Koide N, Fujimori M, et al. Cardiac myxoma: its origin and tumor characteristics. Ann Thorac Cardiovasc Surg. 2003;9(4):215-21.

3. Li H, Guo H, Xiong H, Xu J, Wang W, Hu S. Clinical features and surgical results of right atrial Myxoma. J Card Surg. 2016;31(1):15-7.

4. Yokomuro $\mathrm{H}$, Yoshihara $\mathrm{K}$, Watanabe $\mathrm{Y}$, Shiono N, Koyama N, Takanashi Y. The variations in the immunologic features and interleukin- 6 levels for the surgical treatment of cardiac myxomas. Surg Today. 2007;37(9):750-3.

5. Larsson S, Lepore $V$, Kennergren C. Atrial myxomas: results of 25 years' experience and review of the literature. Surgery. 1989;105(6):695-8.

6. Gosev I, Paic F, Duric Z, Gosev M, Ivcevic S, Jakus FB, et al. Cardiac myxoma the great imitators: comprehensive histopathological and molecular approach. Int J Cardiol. 2013;164(1):7-20.

7. Pinede $L$, Duhaut $P$, Loire R. Clinical presentation of left atrial cardiac myxoma. A series of 112 consecutive cases. Medicine (Baltimore). 2001;80(3): 159-72.

8. Sarjeant JM, Butany J, Cusimano RJ. Cancer of the heart: epidemiology and management of primary tumors and metastases. Am J Cardiovasc Drugs. 2003;3(6):407-21.

9. Citro R, Masiello P, Bossone E, Provenza G, Mastrogiovanni G, Baldi C, et al. Giant left atrial myxoma: an unusual cause of acute pulmonary edema. J Am Soc Echocardiogr. 2008;21(8):971-8.

10. Bjessmo S, Ivert T. Cardiac myxoma: 40 years' experience in 63 patients. Ann Thorac Surg. 1997;63(3):697-700.

11. Barh D, Kumar A, Chatterjee S, Liloglou T. Molecular features, markers, drug targets, and prospective targeted therapeutics in cardiac myxoma. Curr Cancer Drug Targets. 2009;9(6):705-16.

\section{Publisher's Note}

Springer Nature remains neutral with regard to jurisdictional claims in published maps and institutional affiliations. 